\title{
DUKUNGAN EMOSIONAL KELUARGA DENGAN TINGKAT KECEMASAN PADA PASIEN TUBERKULOSIS (TB) PARU
}

\author{
Lisa Ari Rusmilah ${ }^{l)}$, Atiek Murharyati ${ }^{2)}$, Maula Mar'atus Solikhah ${ }^{3)}$, Erinda Nur Pratiwi ${ }^{4)}$ \\ ${ }^{1)}$ Mahasiswa Program Studi Keperawatan Program Sarjana Universitas Kusuma Husada Surakarta \\ ${ }^{2)}$ Dosen Prodi Sarjana Keperawatan Universitas Kusuma Husada Surakarta \\ ${ }^{3)}$ Dosen Prodi Diploma Keperawatan Universitas Kusuma Husada Surakarta \\ 4) Dosen Prodi Pendidikan Profesi Bidan Program Profesi Universitas Kusuma Husada Surakarta \\ Email:lisaarir@gmail.com ${ }^{l)}$,murharyatiatik@gmail.com ${ }^{2)}$,pratiwierinda@gmail.com ${ }^{4)}$
}

\begin{abstract}
Tuberculosis (TB) is an infectious disease, most of which is caused by Mycobacterium tuberculosis. The psychological effect that is often experienced by TB patients is anxiety. There factors that cause anxiety, predisposition and precipitation. One of the factors that influence someone in dealing with anxiety is family support. Especially in emotional support, which can promote feelings of comfort and emotional control in TB patients. The purpose of this study was to determine the relationship between family emotional support and anxiety levels in pulmonary tuberculosis (TB) patients.

This research was conducted in the Wonogiri District area. The research design used crosssectional. The total sampling was $(n=59)$ in TB patients who are undergoing treatment. The research tool uses a questionnaire. Data analysis used Chi Square Test.

Date were retrieved by questionnaire then analyzed using chi square with degree of meaning $\alpha<0.05$. Result and analyze, obtained $p$ value 0.034 ( $p$-value $0.034<\alpha(0.05)$, it means that Ho is rejected and $\mathrm{Ha}$ is accepted. The results a relationship between family emotional support and the anxiety level of pulmonary tuberculosis (TB) patients in Wonogiri District.
\end{abstract}

Keywords : family emotional support, anxiety level, tuberculosis (tb) patients

\section{ABSTRAK}

Tuberkulosis (TB) adalah suatu penyakit menular, yang sebagian besar disebabkan oleh kuman Mycobacterium tuberculosis, dampak psikologis yang sering dialami pasien TB salah satunya yaitu kecemasan, faktor penyebab kecemasan, predisposisi dan presipitasi. Salah satu faktor yang berpengaruh bagi seseorang dalam menghadapi kecemasan adalah dukungan keluarga. Khususnya pada dukungan emosional, yang dapat mendorong perasaan nyaman dan penguasaan emosi pada pasien TB. Tujuan penelitian ini untuk mengetahui hubungan dukungan emosional keluarga dengan tingkat kecemasan pasien tuberkulosis (TB) paru.

Penelitian ini dilakukan di wilayah Kecamatan Wonogiri. Desain penelitian menggunakan crosssectional. Pengambilan sampel dengan total sampling, sebanyak $(\mathrm{n}=59)$ pada penderita TB yang sedang menjalani pengobatan. Alat penelitian menggunakan kuesioner. Analisa data menggunakan Uji Chi Square.

Data yang diperoleh didapatkan dari kuesioner kemudian dianalisis menggunakan chi square dengan derajat pemaknaan $\alpha<0.05$, hasi dan analisis didapatkan $\mathrm{p}$ value 0,034 , ( $\mathrm{p}$ value $0,034<\alpha$ $(0,05)$ maka berarti Ho ditolak dan Ha diterima hasilnya ada hubungan dukungan emosional keluarga dengan tingkat kecemasan pasien tuberkulosis (TB) paru di Wilayah Kecamatan Wonogiri.

Kata kunci : dukungan emosional keluarga, tingkat kecemasan, pasien tuberkulosis (tb) 


\section{PENDAHULUAN}

\section{Latar Belakang}

Tuberkulosis (TB) merupakan penyakit infeksi yang masih menjadi masalah baik di pengobatan maupun diagnosis (Kurniawan 2016). Secara global World Health Organization (WHO) mengatakan, pada tahun 2018 diperkirakan 10,0 juta (kisaran 9,0-11,1 juta) 2 orang jatuh sakit karena TB jumlah yang relatif stabil dalam beberapa tahun terakhir. Diperkirakan ada sekitar 1,2 juta (kisaran, 1,1-1,3 juta) kematian akibat tuberkulosis (TB) paru, TB menyerang semua jenis kelamin dan semua kelompok umur, tetapi yang tertinggi adalah pada pria (15 tahun ke atas), yang menyumbang $57 \%$ dari semua kasus $\mathrm{TB}$ pada tahun 2018. Secara geografis, kasus TB pada 2018 yaitu dengan kisaran di Asia Tenggara (44\%), Afrika (24\%) dan Pasifik Barat (18\%), dengan persentase lebih kecil di Mediterania Timur (8\%), Amerika (3\%) dan Eropa (3\%). Indonesia (8\%) menempati peringkat ketiga penderita TB terbesar setelah India dan China (WHO, 2019).

Jumlah kasus baru TB di Indonesia sebanyak 420.994 kasus pada tahun 2017 (data per 17 Mei 2018). Berdasarkan jenis kelamin, jumlah kasus baru TBC tahun 2017 pada laki-laki 1,4 kali lebih besar dibandingkan perempuan (KEMENKES RI, 2017).

Jumlah kasus tertinggi yang dilaporkan terdapat di tiga provinsi yaitu Jawa Barat 77,7\%, Jawa Tengah 80,8\%,Jawa Timur 58,9\%, Penemuan kasus baru di Jawa Tengah sebesar 194 per 100.000 penduduk. (Ditjen P2P, Kemenkes RI, 2019). Untuk Daerah Wonogiri sendiri CNR seluruh kasus TB per 100.000 penduduk adalah 56,34. Dari data yang di dapat di Puskesmas Wonogiri I ada 11 kasus pasien TB dan di Puskesmas Wonogiri II ada 88 kasus pasien Tb (Dinkes Wonogiri, 2015).

Tuberkulosis (TB) paru merupakan suatu penyakit menular yang disebabkan oleh bakteri Mycobacterium tuberculosis (M.Tb). (Karimah, 2019). Dampak psikologis pasien TB yang sering dialami adalah masalah emosional seperti perasaan bosan dan cemas (Suryani et al. 2016). Menurut Shen et al, (2014). Pasien yang diagnosis TB paru, timbul perasaan cemas serta ketakutan dalam dirinya, yang berupa ketakutan akan pengobatan yang akan di jalaninya, kematian, efek samping obat, menularkan penyakit ke orang lain, kehilangan pekerjaan, ditolak dan diasingkan Menurut Peplau (1952) dalam Suliswati (2014) ada empat tingkat kecemasan : Kecemasan ringan, Kecemasan sedang, Kecemasan berat dan Panik.

Salah satu faktor yang dapat berpengaruh bagi seseorang ketika sedang menghadapi masalah, khususnya masalah kesehatan adalah dukungan keluarga, hal ini juga sebagai strategi dalam mencegah stres. Dukungan keluarga dalam hal penurunan cemas sangat diperlukan, (Viany et al, 2019).

Khususnya pada dukungan emosional, karena dukungan emosional adalah satu dukungan keluarga yang paling di butuhkan dalam penurunan kecemasan karena Berfungsi sebagai pelabuhan istirahat dan pemulihan, serta membantu penguasaan emosional, meningkatkan moral keluarga tersebut (Friedman, Bowden \& Jones, 2010).

Menurut Sarafino \&Timothy (2011), Dukungan emosional sebagai srategi yang tepat 
dalam penuruan kacemasan karena melibatkan ekspresi empati, perhatian, pemberian semangat, kehangatan pribadi, cinta, atau bantuan emosional. Dengan semua tingkah laku yang mendorong perasaan nyaman dan mengarahkan individu untuk percaya bahwa ia dipuji, dihormati, dan dicintai, dan bahwa orang lain bersedia untuk memberikan perhatian Sehingga penelitian ini bertujuan untuk mengetahui dukungan emosional keluarga dengan tingkat kecemasan pada pasien tuberkulosis (TB) di Wilayah Kecamatan Wonogiri.

\section{METODE}

Penelitian yang di lakukan ini merupakan penelitian kuantitatif dengan metode analitik, desain penelitian ini menggunakan crosssectional, Teknik pengambilan sampelnyatotal sampling, dengan jumlah responden 59 pasien TB, Lokasi penelitian di Wilayah Kecamatan Wonogiri (Puskesmas Wonogiri 1 \& Puskesmas Wonogiri 2).

Penelitian ini terdapat variable independen yaitu dukungan emosional keluarga dan variabel dependen yaitu tingkat kecemasan. Kuesioner dukungan keluarga menggunakan family support questionnaire milik penelitian Biswas, Thaniwattananon \&Nilmanat, (2010). lalu di kembangkan oleh Solikhah, Nursasi \& Wiarsih, (2019). Isi kuesioner dukungan emosional keluarga terdiri dari 10 pernyataan dukungan emosional. Sedangkan untuk mengukur tingkat kecemasan menggunakan kuesioner HARS (Hamiltone Anxity Rating Scale) yang dibuat oleh Hamilton tahun (1959).

Analisis data univariate disajikan dalam bentuk distribusi frekuensi dan presentase dari dukungan emosional keluarga dan tingkat kecemasan.Untuk analisa bevariate untuk mengidentifikasi tipe hubungan dukungan emosional keluarga, untuk semua data penelitian, di dapatkan data tidak terdistribusi normal. Dukungan emosional kategori kurang (total skor $<34$ ) dan baik (total skor >34).

Untuk data tingkat kecemasan di kategorikan menjadi kurang dari 14 (tidak ada kecemasan), 14-20 (ringan), 21-27 (sedang), 2841 (berat), $42-56$ (sangat berat). Analisa bevariate menggunakan Chi Square dengan kaidah keputusan $p$ value <0.05. Sedangkan untuk mengetahui derajat hubungan menggunakan Odds Ratio (OR) cara lain mencari OR yaitu dengan Dummy variabel

\section{HASIL}

\section{Karakteristik Responden}

Tabel 1. Karakteristik responden berdasarkan umur pasien tuberkulosis (tb) paru di sajikan dalam bentuk frekunsi dan presentase (n:59)

\begin{tabular}{ccc}
\hline Umur & $\mathrm{F}$ & $(\%)$ \\
\hline $15-25$ & 11 & 18,6 \\
Tahun & & \\
$26-35$ & 5 & 8,5 \\
Tahun & & 20,3 \\
$36-45$ & 12 & 25,4 \\
Tahun & & \\
$46-55$ & 15 & 18,6 \\
Tahun & & \\
$56-65$ & 11 & 8,5 \\
Tahun & & \\
$66-75$ & 5 & 100 \\
Tahun & &
\end{tabular}


Vol. 16 No. 1 Januari - April 2021

Berdasarkan hasil penelitian yang telah dilakukan menunjukan bahwa mayoritas yang terkena TB di Wilayah Kecamatan Wonogiri adalah pada rentang usia 46-55 tahun atau pada usia produktif

Tabel 2. Karakteristik responden berdasarkan jenis kelamin pasien tuberkulosis (tb) paru di sajikan dalam bentuk frekunsi dan presentase (n:59)

\begin{tabular}{ccc}
\hline Jenis kelamin & $\mathrm{F}$ & $(\%)$ \\
\hline Laki-laki & 36 & 61,0 \\
Perempuan & 23 & 39,0 \\
\hline $\mathrm{N}$ & 59 & 100 \\
\hline
\end{tabular}

Berdasarkan hasil penelitian yang telah dilakukan menunjukkan mayoritas penderita TB paru di Wilayah Kecamatan Wonogiri adalah lakilaki

Tabel 3. Karakteristik responden berdasarkan status merokok pasien tuberkulosis (tb) paru di sajikan dalam bentuk frekunsi dan presentase (n:59)

Berdasarkan hasil penelitian yang telah

\begin{tabular}{ccc}
\hline Status Merokok & $\mathrm{F}$ & $(\%)$ \\
\hline Merokok & 0 & 0 \\
Tidak Merokok & 59 & 100,0 \\
\hline $\mathrm{N}$ & 59 & 100
\end{tabular}

dilakukan di Kecamatan Wonogiri, menunjukan responden yang terkena TB tidak merokok.

Tabel 4. Karakteristik responden berdasarkan lama pengobatan pasien tuberkulosis (tb) paru di sajikan dalam bentuk frekunsi dan presentase

$$
\text { (n:59) }
$$

\begin{tabular}{lcc}
\hline Tingkat Kecemasan & F & $(\%)$ \\
\hline Tidak ada kecemasan & 8 & 13,6 \\
Kecemasan ringan & 41 & 69,5 \\
Kecemasan sedang & 6 & 10,2 \\
Kecemasan berat & 4 & 6,8 \\
\hline \multicolumn{1}{c}{$\mathbf{5}$} & $\mathbf{5 9}$ & $\mathbf{1 0 0}$ \\
\hline
\end{tabular}

Berdasarkan hasil penelitian yang telah dilakukan di Kecamatan Wonogiri menunjukan bahwa responden yang terkena TB rata-rata sudah menjalani pengobatan lanjutan atau lebih dari 3 bulan, pasien TB harus menyelesaikan pengobatan selama 6 bulan, tapi ada pula yang lebih dari 6 bulan karena bakteri yang ada di paruparu masih ada

\section{Dukungan emosional}

Tabel 5. Hasil dukungan emosional pasien tuberkulosis (TB) paru dijelaskan menggunakan ditribusi frekuensi dengan ukuran presentase $(n=59)$

\begin{tabular}{ccc}
\hline $\begin{array}{c}\text { Dukungan } \\
\text { Emosional }\end{array}$ & $\mathrm{F}$ & $(\%)$ \\
\hline Baik & 33 & 55,9 \\
Kurang & 26 & 44,1 \\
\hline $\mathrm{N}$ & 59 & 100
\end{tabular}

Berdasarkan hasil penelitian menunjukan bahwa dukungan emosional yang diberikan keluarga terhadap pasien TB di Wilayah Kecamatan Wonogiri dalam katagori cukup baik, tapi masih kurang maksimal karena dukungan kurang dan dukungan baik hampir sama

3. Hasil tingkat kecemasan pasien tuberkulosis

(TB)

\begin{tabular}{clc}
\hline $\begin{array}{c}\text { Lama } \\
\text { Pengobatan }\end{array}$ & $\mathrm{F}$ & $(\%)$ \\
\hline 2 Bulan & 10 & 16,9 \\
3 Bulan & 10 & 16,9 \\
4 Bulan & 13 & 22,0 \\
5 Bulan & 11 & 18,6 \\
6 Bulan & 15 & 25,4 \\
\hline $\mathrm{N}$ & 59 & 100
\end{tabular}

Tabel 5. Hasil tingkat kecemasan pasien tuberkulosis (TB) paru dijelaskan menggunakan ditribusi frekuensi dengan ukuran presentase $(\mathrm{n}=59)$ 
Berdasarkan hasil penelitian yang telah dilakukan menunjukkan tingkat kecemasan pasien $\mathrm{TB}$ di

Wilayah Kecamatan Wonogiri rata-rata mengalami kecemasan ringan meskipun begitu, ada beberapa responden yang mengalami kecemasan berat, sehingga harus dan perlu di waspadai agar tidak mengalami kecemasan yang lebih berat lagi.

4. Hubungan dukungan emosional dengan tingkat kecemasan pasien tuberculosis (TB) paru di Wilayah Kecamatan wonogiri

Tabel 6. Hubungan dukungan emosional dengan tingkat kecemasan pasien tuberculosis (TB) paru di Wilayah Kecamatan wonogiri

$$
(n=59)
$$

\begin{tabular}{|c|c|c|c|c|c|c|c|c|c|c|}
\hline \multirow{3}{*}{$\begin{array}{l}\text { Dukungan } \\
\text { Emosional }\end{array}$} & \multicolumn{7}{|c|}{ Tingkat Kecemasan } & \multirow{3}{*}{ Total } & \multirow{3}{*}{$\begin{array}{c}\mathrm{P} \\
\text { value }\end{array}$} & \multirow{3}{*}{ OR } \\
\hline & \multicolumn{2}{|c|}{$\begin{array}{l}\text { Tidak ada } \\
\text { kecemasan }\end{array}$} & $\begin{array}{l}\text { Kecemasan } \\
\text { ringan }\end{array}$ & \multicolumn{2}{|c|}{$\begin{array}{l}\text { Kecemasan } \\
\text { sedang }\end{array}$} & \multicolumn{2}{|c|}{$\begin{array}{l}\text { Kecemasan } \\
\text { berat }\end{array}$} & & & \\
\hline & $\mathrm{n}$ & $\%$ & $\mathrm{n} \quad \%$ & $\mathrm{n}$ & $\%$ & $\mathrm{n}$ & $\%$ & & & \\
\hline Baik & 7 & $21,2 \%$ & $2266,7 \%$ & 4 & $12.1 \%$ & 0 & $0,0 \%$ & $\begin{array}{l}33 \\
100 \% \\
\end{array}$ & \multirow{3}{*}{0,034} & \multirow{3}{*}{$\begin{array}{c}9.5 \\
(1,909- \\
2,346)\end{array}$} \\
\hline Kurang & 1 & $3,8 \%$ & $1973,1 \%$ & 2 & $7.7 \%$ & 4 & $15,4 \%$ & $\begin{array}{l}26 \\
100 \% \\
\end{array}$ & & \\
\hline Total & 8 & $13,6 \%$ & $4169,5 \%$ & 6 & $10,2 \%$ & 4 & $6,8 \%$ & $\begin{array}{l}59 \\
100 \%\end{array}$ & & \\
\hline
\end{tabular}

Berdasarkan hasil penelitian ini didapatkan bahwa hasil dukungan emosional keluarga ada hubunganya dengan tingkat kecemasan yang dialami pasien tuberkulosis (TB), semakin tinggi dukungan yang diberikan maka akan semakin rendah pasien mengalami kecemasan yaitu sebesar 7 responden $(21,2 \%)$, karena dukungan ini memiliki peran penting menyangkut psikologis dan mental yang dapat meningkatkan motivasi penderita untuk sembuh hal ini dikarenakan dukungan emosional keluarga mencakup ungkapan empati, kepedulian, dan perhatian terhadap penderita TB yang di berikan keluarga selaku pihak yang paling dipercaya oleh penderita. 
Jurnal Ilmiah Pannmed (Pharmacyst, Analyst, Nurse, Nutrition, Midwivery, Environment, Dental Hygiene)

Vol. 16 No. 1 Januar i - April 2021 


\section{PEMBAHASAN}

Berdasarkan tabel 1 responden Tuberkulosis (TB) di wilayah kecamatan wonogiri pada bulan Juni 2020. Pasien yang paling banyak terkena tuberkulosi (TB) paru rentang usia 46-55 tahun dengan jumlah 15 $(25,4 \%)$. Hal ini sejalan dengan penelitian yang di lakukan Murdianto (2016) di Sibela Mojosongo bahwa mayoritas pasien yang menderita TB paru pada usia 36-55 tahun. Dan didukung oleh penelitian, Wadjah (2012) yang mengungkapkansebagian besar penderita TB usia 25-55 tahun

Menurut Depkes RI (2013) yang menyatakan bahwa $75 \%$ penderita TB Paru pada rentang usia produktif (15-50 tahun). Ma'arif. K (2012) pada penelitian yang di lakukannya menyatakan bahwa penderita TB terbanyak pada usia produktif, cenderung mempunyai mobilitas yang cukup tinggi dalam hal pekerjaan maupun gaya hidup, keadaan tersebut yang membuat usia produktif lebih mudah terpapar penyakit TB.

Berdasarkan hasil penelitian yang telah dilakukan menunjukan bahwa kebanyakan yang terkena TB di Wilayah Kecamatan Wonogiri adalah pada rentang usia 46-55 tahun atau pada usia produktif, dikarena usia produktif adalah usia yang mempuyai mobilitas yang cukup tinggi sehingga kemungkinan besar untuk terpaparnya kuman Mycobacterium tuberculosis paru lebih besar, jadi usia produktif lebih cenderung terkena penyakit TB lebih besar.

Berdasarkan table 2 responden tuberkulosis (TB) di wilayah kecamatan wonogiri pada bulan juni 2020. Pasien yang terkena tuberkulosi (TB) paru mayoritas adalah laki-laki dengan jumlah 36 responden $(61,0 \%)$. Hal ini sejalan dengan penelitian Murdianto (2016) di Sibela Mojosongo terdapat 16 responden dari jumlah 30 responden. Dan didukung oleh penelitian, milik Wadjah (2012). Yang mengungkapkan bahwa pada jenis kelamin laki-laki lebih tinggi, dikarenakan merokok dan minum alkohol dapat menurunkan sistem pertahanan tubuh.

Berdasarkan hasil penelitian yang telah dilakukan menunjukkan kebanyakan penderita TB paru di Wilayah Kecamatan Wonogiri adalah laki-laki. Itu dikarenakan banyak laki-laki yang usia produktif lebih beresiko terkena TB dari pada perempuan hal ini di karenakan kecenderungan faktor gaya hidup laki-laki yang merokok dan minum-minuman beralkohol, selain itu kebanyakan laki-laki bekerja diluar rumahkemungkinan tertular kuman TB lebih besar.

Berdasarkan status merokok pasien yang terkena tuberkulosi (TB) paru di Kecamatan Wonogiri 59 responden tidak merokok. Hal ini sejalan dengan penelitian Ernawati,K, et al (2017). di Sulawesi Utara tidak terdapat hubungan antara kebiasaan merokok dengan kejadian TB Paru dan penelitian ini di dukung oleh penelitian Soetioso (2014). yang menunjukkan tidak didapatkan hubungan yang signifikan antara kebiasaan merokok dengan derajat kepositivan hasil pemeriksaan sputum BTA.

Menurut Kurniasari dkk (2012), meskipun kebiasan merokok sudah membudidaya dikalangan laki-laki tapi kebiasaan merokok atau status merokok tidak 
Vol. 16 No. 1 Januar i - April 2021

ada hubungan nya dengan terjadinya TBC, terkenanya bakteri Mycobacterium tuberculosis, biasanya dikarenakan lingkungan yang kotor dan status sosial ekonomi. Hal ini berbeda dengan hasil penelitian Romlah (2015), yang menunjukkan bahwa ada hubungan yang signifikan antara pernah merokok dengan kejadian TB Paru dengan besar risiko 3,44 kali lebih besar pada kasus dibanding pada control.

Berdasarkan hasil penelitian yang telah dilakukan di Kecamatan Wonogiri, menunjukan responden yang terkena TB tidak merokok, meskipun begitu orang merokok dapat dengan mudah tertular TB sehingga diharapkan untuk tetap menjaga kebersihan lingkungan sekitar dan menghindari rokok.

Berdasarkan table 3 responden tuberkulosis (TB) di Wilayah Kecamatan Wonogiri pada bulan juni 2020, hasil penelitian yang dilakukan pada 59 responden, pasien tuberkulosi (TB) paru di Wilayah Kecamatan Wonogiri. Dari data yang di peroleh menunjukan, bahwa sebagian besar lama pengobatan 6 bulan dengan 15 responden $(25,4 \%)$. Hal ini sejalan dengan penelitian yang di lakukan oleh Andika (2016) di pontianak terdapat 13 responden dari jumlah 20 responden yang lama pengobatan $>3$ bulan.

Penelitian ini di dukung oleh penelitian Indrayani (2011) yang menyebutkan lama mengonsumsi obat pada pasien TB paru di wilayah Puskesmas Gemolong sebagian besar 4 sampai 6 bulan. Waktu yang diperlukan penderita TB Paru dalam menjalani pengobatan sampai dinyatakan sembuh selama 6 bulan. Jika penderita TB Paru tidak teratur minum obat, maka kuman TB Paru akan kebal sehingga penyakitnya lebih sulit diobati, penderita akan membutuhkan waktu yang lebih lama untuk sembuh, dan masa pengobatan jadi semakin panjang (Anggraeni, 2011).

Berdasarkan hasil penelitian yang telah dilakukan di Kecamatan Wonogiri menunjukan bahwa responden yang terkena TB rata-rata sudah menjalani pengobatan lanjutan atau lebih dari 3 bulan, pasien TB harus menyelesaikan pengobatan selama 6 bulan, tapi ada pula yang lebih dari 6 bulan karena bakteri yang ada di paruparu masih ada.

Berdasarkan table 4 diketahui secara umum dukungan emosional yang diperoleh pasien tuberkulosis (TB) paru diwilayah Kecamatan Wonogiri berdasarkan penelitian yang di lakukan pada 59 responden, pasien tuberculosis (TB) paru di wilayah Kecamatan Wonogiri. dukungan emosional baik sebesar 33 responden $(55,9 \%)$ lebih besar dari pada jumlah dukungan emosional kurang yaitu 26 responden $(44,1 \%)$, yang mana dukungan baik dengan dukungan kurang memiliki selisih yang cukup banyak yatu 7 responden. Hal ini sejalan dengan penelitian yang dilakukan oleh Terok, Bawontong, Untu (2012) dari hasil penelitian yang di lakukan rata-rata dukungan emosional yang di berikan keluarga adalah tinggi. Menurut Friedman, Bowden \& Jones (2010), Dukungan ini berfungsi sebagai pelabuhan istirahat dan pemulihan bantuan dalam penguasaan emosional serta peningkatan moral keluarga dan mengarah individu untuk percaya bahwa ia dicintai. 
Berdasarkan hasil penelitian menunjukan bahwa dukungan emosional yang diberikan keluarga terhadap pasien TB di Wilayah Kecamatan Wonogiri dalam katagori cukup baik, tapi masih kurang maksimal karena dukungan kurang dan dukungan baik hampir sama, oleh sebab itu dukungan emosional harus di tingkatkan agar tidak ada keluarga yang dalam memberikan dukungan kurang, menurut peneliti selama menjalani pengobatan Pasien TB sering menderita secara emosional, sedih, dan kehilangan harga diri, oleh sebab itu dukungan emosional sangat dibutuhkan untuk penguasaan emosional pasien TB.

Sehingga pernyataan tentang keluarga memberikan dukungan untuk hal-hal yang harus dilakukan sebagai bagian dari pengobatan antara lain keluarga memiliki perhatian pada gejala yang berhubungan dengan penyakit yang terjadi pada pasien, keluarga memberi semangat ketika pasien merasa bosan dalam menjaga kesehatan, keluarga memberikan semangat agar pasien menjaga ibadah sesuai agamanya, keluarga menemani rileks menonton $\mathrm{tv}$, mendengarkan radio, dan bercerita lucu, keluarga membantu kepercayaan bahwa pasien akan cepat sembuh, keluarga tetap menyukai dan memperhatikan pasien, keluraga menanyakan perasaan pasien selama pengobatan, kelurga tidak sensitif tentang perubahan sikap, keluarga selalu mendengarkan pasien saat berbicara, di harapakan semua pernyatan tentang dukungan ini dapat ditingkatkan agar pasien mendapatkan dukungan baik lebih tinggi dari pada dukungan kurang.

Berdasarkan table 5 diketahui bahwa secara umum tingkat kecemasan yang diperoleh pasien tuberculosis (TB) paru diwilayah
Kecamatan Wonogiri Berdasarkan penelitian yang di lakukan pada 59 responden, pasien tuberculosis (TB) paru di wilayah Kecamatan Wonogiri. Dari data yang di peroleh mayoritas pasien tuberkulosis mengalami kecemasan ringan dengan jumlah 41 responden $(69,5 \%)$. Dari hasil tersebut terlihat bahwa tingkat kecemasan penderita TB Paru bervariasi ada yang merasakan kecemasan ringan dan ada pula yang merasakan kecemasan sedang. Hal ini sejalan dengan penelitian yang dilakukan oleh Fridayani (2017), rata-rata pasien TB mengalami kecemasan ringan.

Durand \& Barlow (2010) mengatakan kecemasan adalah keadaan suasana hati yang ditandai oleh afek negatif dan gejala-gejala ketergantungan jasmaniah dimana seseorang dapat mengantisipasi datangnya bahaya atau kemalangan dimasa yang akan datang dengan perasaan khawatir. Berdasarkan hasil penelitian yang telah dilakukan menunjukkan tingkat kecemasan pasien TB di Wilayah Kecamatan Wonogiri rata-rata mengalami kecemasan ringan meskipun begitu, ada beberapa responden yang mengalami kecemasan berat,sehingga harus dan perlu diwaspadai agar tidak menglami kecemasan yang leboh berat lagi.

Berdasarkan hasil tabel 6 uji statistik menunjukan uji Chi Square didapatkan p value 0,034, hal ini menunjukan bahwa ada hubungan dukungan emosional dengan tingkat kecemasan pasien tuberculosis (TB) paru di Wilayah Kecamatan Wonogiri. Dengan hasil nilai $p$-value sebesar $0,034<\alpha(0,05)$ maka hal ini berarti Ho di tolak dan Ha di terima sehingga ada hubungan dukungan emosional dengan tingkat kecemasan pasien tuberkulosis (TB) paru di wilayah Kecamatan Wonogiri, Dari analisis diperoleh pula 
$\mathrm{OR}=9,5$ artinya dukungan emosional yang kurang mempunyai peluang 9,5 mengalami kecemasan berat, jadi apabila dukungan emosional keluarga yang diberikan kurang pasien TB dapat mengalami kecamasan berat 9,5 kali, sehingga lebih beresiko dapat mengalami depresi.

Dukungan emosional keluarga terhadap penderita sangat dibutuhkan karena dukungan ini dapat meningkatkan harga diri dan menurunkan kecemasan penderita TB, karena sebelumnya penderita TB selalu menghindar dan mengisolasi diri karena merasa penyakit ini sebuah kutukan dan memalukan karena dapat menularkan ke orang lain, dijelaskan orang yang memperoleh dukungan secara emosional merasa lega karena di perhatikan, mendapat saran atau kesan yang menyenangkan pada dirinya, kasih sayang diantara anggota keluarga. Hal ini penting bagi perilaku kesehatan dan menjadi sehat. Sehingga penderita TB yang mendapat dukungan emosional baik mengalami harga diri yang tinggi. (Berkanis, A T Merianti. 2019).

Hal ini sejalan dengan penelitian yang dilakukan Berkanis, A T Merianti. (2019). menjelaskan bahwa terdapat ubungan dukungan pengaruh emosional keluarga penderita tuberculosis (TB) Terhadap Harga Diri Penderita tuberculosis (TB), Selain itu penelitian ini juga didukung oleh Terok, M,P., Bawotong, J., \& Untu, F,M. (2012). menunjukan ada hubungan dukungan emosional dengan kualitas hidup pasien tuberkulosis paru di Poliklinik Paru BLU RSUP Prof. Dr. R. D Kandou Manado, Dukungan emosional merupakan bagian dari dukungan sosial Dukungan emosional sangatlah penting untuk penderita penyakit kronis (TB Paru) sebab dukungan emosional dapat mempengaruhi tingkah laku seperti penurunan rasa cemas, tidak berdaya, dan putus asa, (PPTI, 2012).

Berdasarkan hasil penelitian ini didapatkan bahwa hasil dukungan emosional keluarga ada hubunganya dengan tingkat kecemasan yang dialami pasien tuberkulosis (TB), semakin tinggi dukungan yang diberikan maka akan semakin rendah pasien mengalami kecemasan, karena dukungan ini memiliki peran penting karena menyangkut psikologis dan mental yang dapat meningkatkan motivasi penderita untuk sembuh hal ini dikarenakan dukungan emosional keluarga mencakup ungkapan empati, kepedulian, dan perhatian terhadap penderita TB yang diberikan keluarga selaku pihak yang paling dipercaya oleh penderita dengan dukungan emosional yang diberikan sehingga dapat menjaga emosi pasien TB agar stabil dan tidak mengalami kenaikan kecemasan

Selain itu sebagai wadah yang aman dan damai yang di berikan guna mencapai pemulihan terhadap permasalahan dukungan yang diberikan ini sebagai faktor utama dalam kesembuhan pasien TB.

\section{KESIMPULAN}

Dari penelitian hubungan dukungan emosional keluarga dengan tingkat kecemasan pasien tuberkulosis (TB) paru diwilayah kecamatan Wonogori di dapatkan

1. Karakteristik penelitian menunjukkan umur sebagian besar berumur 46-55 tahun sebanyak 15 responden (25.4\%), berdasarkan 
jenis kelamin sebagian besar laki-laki dengan 36 responden $(61 \%)$, untuk status merokok menunjukkan bahwa 59 respondentidak merokok dengan, lama pengobatan besar sebagain besar yaitu 6 bulan dengan 15 responden $(25,4 \%)$

2. Dukungan emosional yang diperoleh pasien tuberkulosis (TB) paru diwilayah Kecamatan Wonogiri yaitu dukungan emosional baik sebesar 33 responden $(55,9 \%)$ lebih besar dari pada jumlah dukungan emosional kurang yaitu 26 responden $(44,1 \%)$,

3. Tingkat kecemasan yang diperoleh pasien tuberculosis (TB sebagian besar mengalami kecemasan ringan 41 responden $(69,5)$ dan yangsebagian kecil mengalami kecemasan berat 4 responden $(6.8 \%)$.

4. Adanya hubungan dukungan emosional keluarga dengan tingkat kecemasan pada pasien tuberkulosis (TB) paru di wilayah kecamatan wonogiri dengan didapatkan $p$ value sebesar $0,034<\alpha(0,05)$. Dari analisis diperoleh pula $\mathrm{OR}=9,5$ artinya dukungan emosional yang kurang mempunyai peluang 9,5 mengalami kecemasan berat

\section{DAFTAR PUSTAKA}

1. Andika, S.K. Hubungan Tingkat Kecemasan Dengan Tingkat Kualitas Hidup Pasien Tuberkulosis Paru Di Puskesmas Perumnas Ii Kecamatan Pontianak Barat”. 2016. Skripsi. Program Studi Keperawatan,Fakultas Kedokteran Universitas Tanjungpura Pontianak 2016

2. Anggraeni, D.S. Stop Tuberkulosis. 2011. Jakarta :Bee Media Indonesia

3. Berkanis, Merianti. Article\%20Text-1471-1-10 20191001\%20(1).pdf. 2019.

4. Biswas B.R, Thaniwattananon P \&Nilmanat K. The Relationship Between Family Support and Health B ehaviors among Patients with Pulmonary TB. 2010 The international Conference on Humanities and Social Sciences di akses 10 april 2010 http://fs.libarts.psu.ac.th/ Faculty of Liberal Arts, Prince of Songkla University

5. Depkes RI. Riset Kesehatan dasar. 2013. Jakarta: Badan Penelitian Dan Pengembangan Kesehatan Kementrian Kesehatan RI

6. Dinkes Wonogiri. Profil Kesehatan Kabupaten Wonogiri. 2015. Wonogiri : Dinkes.

7. Durand, M dan Barlow, D. Psikologi Abnormal. 2010. Yogyakarta: Pustaka Pelajar

8. Ernawati, K. dkk. Hubungan Merokok Dengan Kejadian Tuberkulosis Paru di Provinsi Sulawesi Utara Berdasarkan Data Riskesdas Tahun 2010. 2017 Jurnal Kedokteran Yarsi 25 (1) : 033-040 (2017), 106906-ID-hubungan-merokok-dengankejadian-tuberku.pdf

9. Friedman, M. M., Bowden, V.R., \& Jones, E G. 2010. Buku Ajar Keperawatan Keluarga Riset, Teori, Dan Praktik, Edisi 5. Egc: Jakarta

10. Hamilton M. The Assesment of Anxiety States By Rating. 1959. British Journal of Medical Psychology. $32 ; 50$ - 55.

11. Indrayani, R. "Gambaran Tingkat Kecemasan Pasien Tb Paru Ditinjau Dari Lama Konsumsi Obat Tbc Di Wilayah Kerja Puskesmas Gemolong Sragen. 2011. SkripsI. Sarjana Keperawatan. Fakultas Ilmu Kesehatan Universitas Muhammadiyah Surakarta

12. Karimah, K.A. Pengobatan Tuberkulosis Paru Dan Diabetes Melitus Serta Pengaruhnya Terhadap Risiko Multi-Drug Resistant Tuberculosis (MdrTb) Anatomica Medical. 2019. Anatomica Medical Journal ,Vol. 2, No. 1, diakses Januari 2019 http://jurnal.umsu.ac.id/index.php/AMJ

13. Kemenkes RI. Profil Kesehatan Indonesia 2016. 2017. Keputusan Menteri Kesehatan Republik Indonesia. Jakarta.

14. Kurniasari RAS., Suhartono, dan Cahyo, K. Faktor Risiko Kejadian Tuberkulosis Paru di Kecamatan Baturetno Kabupaten Wonogiri. 2012. Media Kesehatan Masyarakat Indonesia, Vol.11/No.2, Oktober 2012

15. Ma'arif.K (2016). "Pengaruh Peranan Pengawas Menelan Obat (Pmo) Terhadap Keberhasilan Pengobatan Tb Paru Di Wilayah Kerja Puskesmas Baki Sukoharjo". Skripsi. Fakultas Ilmu Kesehatan Universitas Muhammadiyah Surakarat. Surakarta.

16. Murdianto, Hapsari I.H \& Rahmawati N. Gambaran Harga Diri Pasien Tuberculosis (Tb) Paru Di Wilayah Kerja Puskesmas Sibela Surakarta. 2016 Skripsi. Stikes Kusuma Husada.Surakarta 


\section{Vol. 16 No. 1 Januari - April 2021}

17. Perkumpulan Pemeberantas Tuberkulosis Indonesia (PPTI). 2012. Jurnal Tuberkulosis Indonesia. Vol8,. http://ppti.info/ArsipPPTI/PPTI Jurnal Maret-2012.pdf, diakses tanggal 8 Mei, 2013.

18. Romlah,L. Hubungan Merokok dengan kejadian Penyakit Tuberkulosis Paru di wilayah kerja Puskesmas Setu Kota Tangerang Selatan. 2015. Skripsi. Fakultas Kedokteran dan Ilmu Kesehatan. UIN Syarif Hidayatullah. Jakarta

19. Sarlito, W.S. Pengantar Psikologi Umum. 2012. Jakarta: Rajawali Pers

20. Sarafino, Edward P., Timothy W. \&Smith. Health Psychology Biopsychosocial Interactions Seventh Edition. 2011. United States Of America

21. Shen, H.K., Budi A. K \& Astuti Y.N. Pengaruh Cognitive Dan Acceptance and Commitment Therapy Terhadap Ansietas, Depresi Klien Tuberculosis. 2014. Jurnal Keperwatan. Vol 9. No 1 Surabaya.

22. Soetioso,VB. Skripsi Hubungan antara Merokok dengan Kejadian Tuberkulosis Paru di RSUD Dr.Soewandhie Surabaya. 2014. Surabaya: Universitas Katolik Widya Mandala

23. Solikhah, M.M, Nursasi, A.Y\&Wiarsih W. The relationship between family's informational support and self efficacy of pulmonary tuberculosis client. 2019. Faculty of nursing Universitas Indonesia, 29(S2):424-427.

24. Suryani, S., Widianti, E., Hernawati, T., \&Sriati, A. Psikoedukasi Menurunkan Tingkat Depresi, Stres Dan Kecemasan Pada Pasien Tuberkulosis Paru. 2016. Jurnal Ners. 11. (1): 128-133.

25. Susilawati, D. Hubungan Dukungan Keluarga Dengan Tingkat Kecemasan Penderita Kanker Serviks di RSUP Dr Sardjito Yogyakarta. 2015. jurnal keperawatan vol 4, no, 2 Diakses 2 desember 2016 https://scholar.google.co.id.

26. Terok, M,P., Bawotong, J., \& Untu, F,M. Hubungan Dukungan Sosial Dengan Kualitas Hidup Pada Pasien Tubekulosis Paru Di Poli Paru Blu Rsup Prof. Dr. R. D Kandou Manado. 2012. Ejournal Keperawatan (E-Kp) Volume. 1 Nomor 1 Agustus 2012. 